\title{
Pielonefritis, colecistitis y cistitis enfisematosas en paciente con diabetes mellitus descompensada*
}

\author{
Drs. TAHITIANA ABELINA ZARAGOZA S. ${ }^{1}$, HUMBERTO OSNAYA M. ${ }^{1}$, \\ MARCO ANTONIO MONDRAGÓN C. ${ }^{1}$, RUBÉN DARÍO SÁNCHEZ R. ${ }^{1}$ \\ Servicio de Cirugía General del Centro Médico Lic. Adolfo López Mateos de Toluca Edo. de México. \\ México.
}

\section{Abstract \\ Pyelonephritis, cholecystitis, and emphysematous cystitis in a diabetic patient}

Background. Emphysematous pyelonephritis is a necrotizing infection characterized by gas production that usually is located in the kidney tissue, urinary tract and retroperitoneal tissue. Gas can escape following the renal veins and accumulate in the hepatic veins and other places. E coli is the most common causative organism. Clinical case: We report a 62 years old diabetic female, admitted to the hospital with a diabetic ketoacidosis. An abdominal CT scan disclosed a left emphysematous pyelonephritis, cholecystitis and cystitis. The patient was operated, performing a left nephrectomy, cholecystectomy and placement of sub hepatic and retroperitoneal drainages. The pathological study of the surgical piece showed an acute pyelonephritis with abscess formation and chronic cholecystitis. The patient died due to a multi systemic failure.

Key words: Emphysematous pyelonephritis, emphysematous cholecystitis emphysematous cystitis, diabetes mellitus 2 .

\section{Resumen}

Introducción: La Pielonefritis enfisematosa es una infección necrotizante caracterizada por la producción de gas, que habitualmente se ubica en el parénquima renal, las vías urinarias y los tejidos retroperitoneales. Cuando el gas es abundante puede escapar siguiendo las venas renales y acumularse en las venas hepáticas, y el resto del sistema. La E. coli es el patógeno más frecuente. Caso clínico: Presentamos el caso de paciente femenina de 62 años, diabética que ingresa con sintomatología de vías urinarias diagnosticada como pielonefritis enfisematosa izquierda por tomografía y encontrando como hallazgos adicionales,

Palabras clave: Pielonefritis enfisematosa, colecistitis enfisematosa, diabetes mellitus tipo 2, cistitis enfisematosa.

*Recibido el 23 de abril de 2012 y aceptado para publicación el 23 de julio de 2012.

Los autores no refieren conflictos de interés.

Correspondencia: Dra. Tahitiana Abelina Zaragoza S.

Calle Tlatelolco \# 633 Colonia Guadalupe, Morelia Michoacán, México.

tatis10018@hotmail.com 


\section{Caso clínico}

Mujer de 62 años de edad, con antecedentes: Cesárea de hace 25 años, hipertensión de 10 años controlada con captopril, diabetes mellitus tipo 2 con tratamiento irregular por desapego del paciente al tratamiento farmacológico. Inicia padecimiento de 10 días de evolución previo a su ingreso con presencia de tenesmo y disuria, acude con facultativo quien inicia tratamiento con antibiótico y analgésico sin presentar mejoría, referida a hospital de segundo nivel donde se da manejo inicial por descontrol

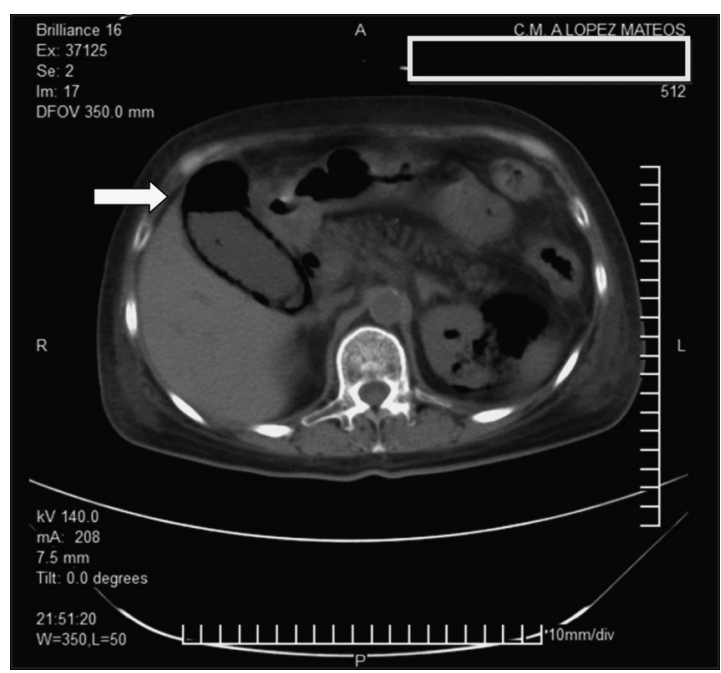

Figura 1. Tomografía de abdomen en fase simple en corte axial. Vesicular biliar con presencia de gas en su paredes, fundus vesicular y perivesicular. Colecistitis enfisematosa.

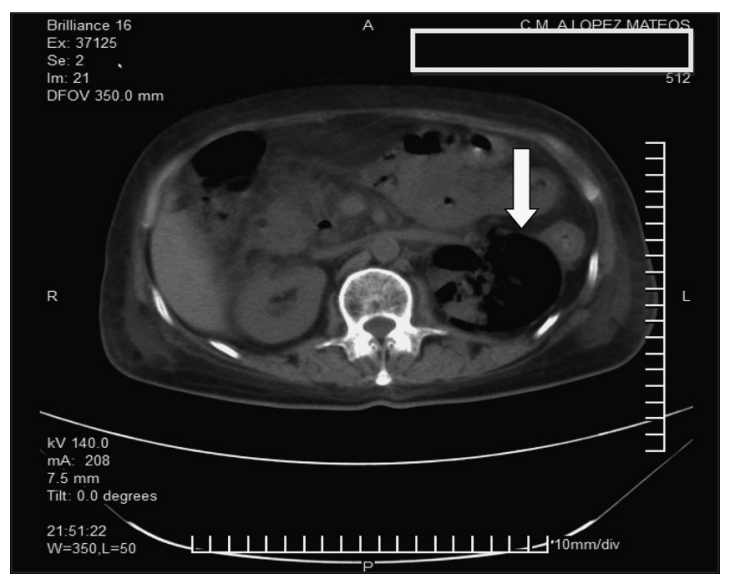

Figura 2. Tomografía de abdomen en fase simple en corte axial, Riñón izquierdo con presencia de gas en pelvis renal, parénquima y región perirenal. Fundus vesicular con presencia de gas. metabólico con cifras de $429 \mathrm{mg} / \mathrm{dl}$ de glucosa iniciando con hidratación y manejo antimicrobiano, sin mejora; es referida a este hospital recibida en urgencias estuporosa, con aliento a cetonas, con funciones mentales no valorables, con pupilas isocóricas normorreflecticas, con buena coloración de tegumentos, deshidratación moderada, cuello con tráquea central sin adenomegalias, campos pulmonares bien aireados, ruidos cardíacos rítmicos de buena intensidad sin agregados, abdomen blando depresible no doloroso a la palpación, no hay datos de irritación peritoneal, peristalsis presente normal, extremidades simétricas, con buen llenado capilar con edema bimaleolar, con arcos de movilidad limitados. Glucometria 429, leucocitos 22,7, Hg 9,8, Hto 28,4 , neutrofilos 92,5 , plaquetas 74 , glicemia 670 , urea 304, creatinina 3,9, INR 1,01. Gasometria: $\mathrm{Ph}$ 7,25, Pco2 18, Po2 82, Hco3 7,9, Pao2 90.

Se establece el diagnóstico de cetoacidosis diabética secundaria a descontrol metabólico por infección de vías urinarias severa, probable pielonefritis. Se decide toma de tomografía abdominal. Hallazgos tomográficos: Tomografía de abdomen en fase simple en corte axial. Vesícula biliar con presencia de gas en sus paredes, fundus vesicular y perivesicular y colecistitis enfisematosa (Figura 1). Riñón izquierdo con presencia de gas en pelvis renal, parénquima y región perirenal, (Figuras 2 y 3). En la Tomografía de abdomen en fase simple en corte sagital se observa riñón izquierdo con presencia de gas en parénquima y espacio perirenal con extensión al trayecto ureteral hasta el tercio distal, probable vejiga (Figura 4). Diagnóstico final: cetoacidosis diabética secundaria a Pielonefritis enfisematosa, la cual requiere tratamiento quirúrgico de urgencia,

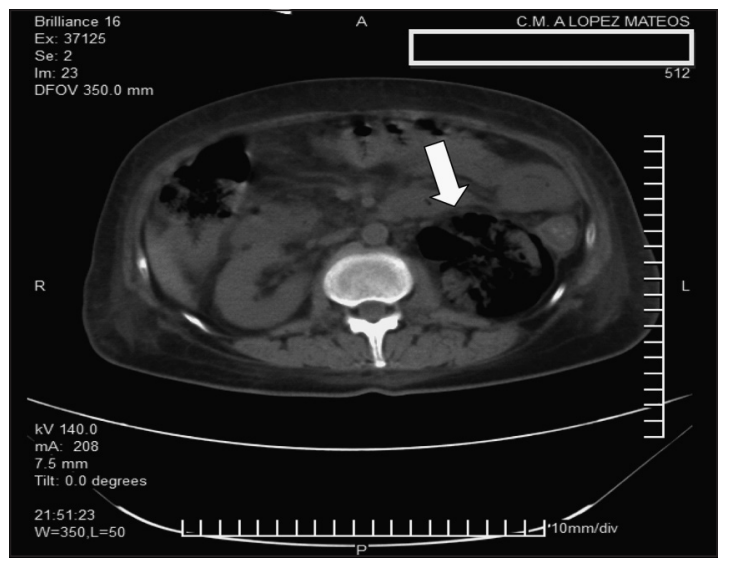

Figura 3. Tomografia de abdomen en fase simple en corte axial, Riñon izquierdo con presencia de gas en pelvis renal, parénquima y región perirenal. 


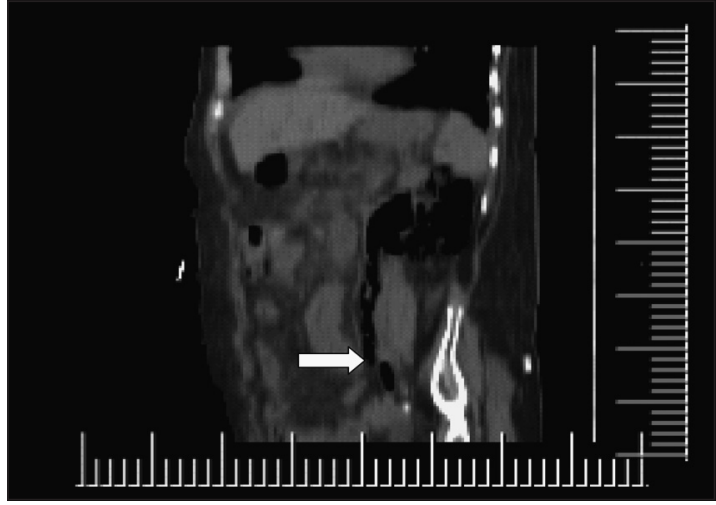

Figura 4. Tomografía de abdomen en fase simple en corte sagital. Riñón izquierdo con presencia de gas en parénquima y espacio perirenal con extensión al trayecto ureteral hasta el tercio distal, probable vejiga.

realizando laparotomía exploradora, nefrectomía simple izquierda, colecistectomía y colocación de drenajes en retroperitoneal izquierdo y subhepáticos. Los hallazgos transoperatorios fueron riñón izquierdo enfisematoso, múltiples adherencias firmes a colon, gas circundante a psoas izquierdo disecando hasta vejiga urinaria; colecistitis enfisematosa encontrando vesícula biliar $12 \times 6 \times 5 \mathrm{~cm}$ con paredes necrosadas, friables, con gas en su interior, cístico de $3 \mathrm{~mm}$ líquido perivesicular de reacción. El estudio histopatológico reporta: Pielonefritis crónica y aguda abscedada multifocal con glomeruloesclerosis nodular y túbulos con necrosis isquémica focal, nefroangioesclerosis y una colecistitis crónica litiásica con agudización incipiente y necrosis isquémica focal de la pared. nica.

La paciente fallece por sepsis y falla multiorgá-

\section{Discusión}

La pielonefritis enfisematosa es una infección necrotizante, caracterizada por la producción de gas que habitualmente se ubica en el parénquima renal, las vías urinarias y los tejidos retroperitoneales ${ }^{1-3} \mathrm{y}$ de acuerdo al caso se puede presentar en cualquier órgano de la economía. El gas puede escapar siguiendo a las venas y a todo el sistema venoso y acumularse en las venas hepáticas, venas renales, vesicales, y distribuirse a todo el sistema por vía circulatoria ${ }^{4,5}$. El gas del riñón afectado, medido cromatográficamente, está constituido por nitrógeno $50 \%$, dióxido de carbono $39 \%$, hidrógeno $10 \%$, oxígeno $1 \%$. Patógenos: La $E$. coli es el patógeno más frecuente, Klebsiella pneumoniae,
Proteus mirabilis, Enterobacter aerogenes, Pseudomona spp, Clostridium spp, Cándida spp y otros hongos, Pneumocystis carinii ${ }^{6,7}$. La infección es polimicrobiana en el $20 \%$ de los casos. En el caso de esta paciente fue polimicrobiana ${ }^{8,9}$. Entre los factores de riesgo están pacientes con diabetes mellitus con mal control glicémico y una alta concentración de glucosa en los tejidos y la orina, la infección con bacterias coliformes capaces de producir dióxido de carbono e hidrógeno por fermentación de la glucosa, la obstrucción del tracto urinario, la perfusión tisular alterada que produce un sustrato de tejido necrobiótico ${ }^{10,11}$. Afecta más a las mujeres, con una proporción de 8:1, relacionado a infección de vías urinarias, siendo la infección unilateral, con predominio del riñón izquierdo hasta en $60 \%$, contralateral a la vesícula biliar también afectada y sistema ureteral ${ }^{12,13}$. En cuanto a laboratoriales, se describe leucocitosis con neutrofilia, examen general de orina con datos compatibles con un proceso infeccioso ${ }^{14}$.

El diagnóstico es tardío, con sospecha por patología de base y antecedentes de infección de vías urinarias, sin síntomas evidentes, pero con datos de laboratorio útiles para diferenciar la pielonefritis de pielonefritis enfisematosa y con signos de sepsis que no responden adecuadamente al tratamiento convencional; es importante la demostración de la presencia de gas en el tracto urinario y a nivel vesicular por un método de imagen, idealmente tomografía axial computada, que identifica el gas y delimita la extensión de la enfermedad.

Dadas las características de esta paciente podemos concluir que podría existir un nuevo síndrome de patología enfisematosa múltiple en el paciente diabético, que nos haría poner atención a una nueva revisión de estos casos, ya que no encontramos en la literatura mundial reporte de patologías asociadas como esta. El diagnóstico oportuno puede mejorar el pronóstico del paciente, interviniendo de manera precoz y adecuada.

La clasificación tomográfica mencionada y descrita en la bibliografía reporta:

1) clase 1: gas en el sistema colector solamente (también llamada pielitis enfisematosa).

2) clase 2: gas en el parénquima renal sin extensión al espacio extrarrenal.

3) clase 3: Clase 3A extensión del gas o absceso al espacio perirrenal. Clase 3B: extensión del gas o absceso al espacio pararrenal.

4) clase 4, pielonefritis enfisematosa (PE) bilateral o riñón único con $\mathrm{PE}$.

El caso de esta paciente no se incluye en ninguna de las clasificaciones actualmente descritas ya que no existe un rubro donde se integre la pielonefritis contralateral a una colecistitis enfisematosa, más 
aun asociada a una cistitis enfisematosa, por lo que proponemos se realicen nuevos estudios de casos seriados en los cuales se pueda crear una nueva escala o clasificación en la que podamos incluir este tipo de patologías para poder dar un nuevo enfoque al paciente con el fin de mejorar su pronóstico.

Tratamiento: El tratamiento descrito en la literatura de las clases III y IV son el uso de antimicrobianos y drenaje percutáneo y/o tratamiento quirúrgico radical de acuerdo a la evolución del paciente. La paciente presentaba plaquetopenia, insuficiencia renal aguda y alteración de la conciencia, así como choque séptico por la evolución prolongada, indicadores conocidos de una mala respuesta terapéutica. En esta paciente la decisión que se tomó fue una intervención radical, lo que, a criterio de los cirujanos, fue lo mejor teniendo en cuenta el curso fulminante y la mortalidad más elevada de los pacientes tratados médicamente. Pese al tratamiento establecido, la mortalidad es alta y variable, se reporta desde $50 \%$ hasta $90 \%$.

Debemos tener en mente la sospecha de afectación a otros órganos aunque no necesariamente adyacentes para el mejor manejo y ofrecer a nuestros pacientes un pronóstico mejor al actualmente descrito en la literatura.

\section{Referencias}

1. Melero MJ, Sarquis SG, Biancolini C, Baredes N, Villa R. Pielonefritis enfisematosa aguda bilateral. Un desafío terapéutico. Medicina (B. Aires) v.67 n.3 Buenos Aires mayo/jun. 2007. Versión on-line SciELO ISNN 16699106.

2. González A, Elizondo S, Carrillo R, Dr. Ramírez JA, Dr. Sánchez M. Pielonefritis enfisematosa, reporte de dos casos y revisión de la literatura. Revista de la Asociación Mexicana de Medicina Crítica y Terapia Intensiva. 2007;XXI:45-50.

3. Walsh. Emphysematous pyelonephritis. In: Campbell's. Urology. 8th edition Elsevier. USA. 2002.
4. Huang JJ, Tseng C. Emphysematous pyelonephritis. Clinic radiological classification management, prognosis, and pathogenesis. Arch Intern Med. 2000;160:797-805.

5. López HM, Chávez DA, Hernández MM, Santiago SR, Rivera BC, Camacho OT, y col. Pielonefritis bilateral y cistitis enfisematosa. Análisis de un caso y revisión de la literatura. Med Int Mex. 2003;19:46-51.

6. Racca ML, Ponzano R, Sarria JP, Minuzzi F, Minuzzi G. Pielonefritis enfisematosa. Comunicación de un caso Arch. Esp. Urol. 2009;62:406-9.

7. Piedra I, Medina JL, Varela L, Zegarra L, Melgarejo W, Medina R, y col. Pielonefritis enfisematosa: Reporte de dos casos y revisión de la literatura. Rev Med Hered. 2007; 18:334-36.

8. Berger RE. Host and bacterial virulence factors predisposing to emphysematous pyelonephritis. J Urol. 2006;175:2121.

9. Blanco A, Barbagelata A, Fernández E, Casas R, Chantada V, González M. Pielonefritis enfisematosa: presentación de un caso y revisión de la literatura. Actas Urol Esp. 2003 http://dx.doi.org/10.4321/S021048062003000900010.

10. Peces R, Fernández J, González E, Peces C. Pielonefritis enfisematosa con absceso perirrenal resueltos con tratamiento médico conservador. Nefrología 2007;27: 145-47.

11. Van der Osten I, López A, Fontana N, Rodríguez O, Castillo N, Araujo O, y col. Pielonefritis Enfisematosa Presentación de caso. Med Interna (Caracas) 2010;26:97-9.

12. Franco-León S, Lazos-Ochoa M, Santiago-Prieto A, Aguirre-Quezada DE. Informe de dos casos con énfasis en aspectos fisiopatológicos. Hospital General de México 2004;67:157-62.

13. France R. Renard-Penna. Tratamiento de las pielonefritis complicadas y de los abscesos renales. Urología 2008;40:1-9.

14. Bermejo YE, Pimentel A. Sensibilidad y especificidad del examen general de orina como prueba de escrutinio para infección de vías urinarias en pacientes con diabetes mellitus sin síntomas urinarios. IMSS 2011;6:16016 . 